\title{
Aspectos histológicos do ovário de coelhas após criopreservação
}

\author{
Histological aspects of rabbit ovarian tissue after cryopreservation
}

Beatriz Angélica Charlotte Thomaz ${ }^{1}$, Maria de Lourdes Pessole Biondo-Simões ${ }^{2}$, Carlos Gilberto Almodin ${ }^{3}$, Vânia Cibele Minguetti-Camara ${ }^{4}$, Álvaro Pigato Ceschin ${ }^{5}$, Sergio Ossamu Ioshii ${ }^{6}$

\section{RESUMO}

Objetivo: avaliar a preservação folicular e as características celulares do tecido ovariano criopreservado, em coelhas. Métodos: fez-se, sob anestesia, a ooforectomia direita de dez coelhas brancas, adultas. Dissecou-se o ovário mantendo-se o córtex com espessura de 1,5 milímetros. Fragmentou-se o tecido em pequenas secções, algumas para o estudo histológico de controle e outras destinadas à criopreservação pelo protocolo de congelamento lento. Passadas seis semanas efetuouse o descongelamento e fez-se a avaliação histológica. As amostras do controle e do experimento, após processamento, foram coradas pela hematoxilina-eosina para identificação dos aspectos histológicos e submetidas à técnica imunohistoquímica utilizando-se o PCNA (proliferating cell nuclear antigen) para a avaliação da viabilidade celular. Utilizaramse os testes não paramétricos "comparação entre duas proporções" e Mann-Whitney e o teste paramétrico $t$ de Student. Resultados: observou-se que no tecido criopreservado só persistiram oócitos primordiais. Entre as alterações reversíveis identificaram-se: vacuolização citoplasmática em todas as amostras $(\mathrm{p}=0,039)$, lise estromal em $50 \%(\mathrm{p}=0,648)$ e oócitos com contornos irregulares em $80 \%(\mathrm{p}=0,007)$. Encontraram-se alterações irreversíveis como degeneração hialina e picnose em $30 \%$ das amostras $(\mathrm{p}=0,210)$. A análise imuno-histoquímica demonstrou os folículos, em diferentes estágios de desenvolvimento, no tecido não congelado e folículos primordiais no tecido criopreservado com positividade para o PCNA, indicando a presença de DNA ativo. Conclusão: no tecido ovariano criopreservado sobrevivem apenas os folículos primordiais; existem alterações histológicas reversíveis (vacuolização citoplasmática, lise estromal, fragmentação das células da granulosa e oócitos com contornos irregulares); alterações irreversíveis, em níveis não significantes (degeneração hialina e picnose) e presença de PCNA positivo em todos os folículos.

PALAVRAS-CHAVE: Criopreservação; Ovário/anatomia \& histologia; Antigeno nuclear de células em proliferação; Coelhos

\section{ABSTRACT}

Purpose: to evaluate follicular preservation and histologic characteristics of the cryopreserved ovarian tissue and to compare with the fresh one, in rabbits. Methods: ten adult female white rabbits were submitted to right oophorectomy. The dried ovary was dissected and the cortex was maintained with approximately 1.5 millimeter thickness. The tissue was fractionated into small sections, some reserved for control histologic study and others destined for cryopreservation. Six weeks later the ovarian tissue was thawed and evaluated histologically. After histologic processing, the control and the experimental samples were stained with hematoxylin and eosin and treated immunohistochemically by the PCNA technique for evaluation of DNA preservation. Histologic alterations present in the fresh and in the cryopreserved tissues were identified, and cryopreserved tissue viability was evaluated. Results: in the cryopreserved tissue only primordial follicles persisted. Reversible alterations were identified: cytoplasmatic vacuolation $(p=0,039)$, stromal lysis $(p=0.648)$ and oocytes with irregular contours ( $\mathrm{p}=0.007)$. Irreversible alterations: (hyalin degeneration and pyknosis) were found, but not at significant

1 Mestre em Ciências da Saúde pela PUCPR, bioquímica da Feliccità - Instituto de Fertilidade, Curitiba.

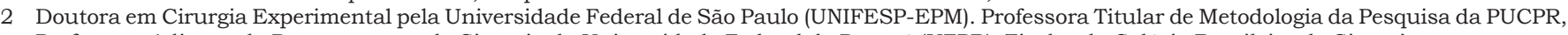
Professora Adjunta do Departamento de Cirurgia da Universidade Federal do Paraná (UFPR), Titular do Colégio Brasileiro de Cirurgiões.

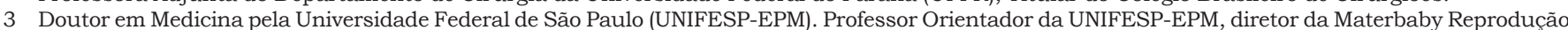
Humana e Genética, Maringá.

4 Mestre em Biologia Celular pela Universidade Estadual de Maringá. Bioquímica da Materbaby Reprodução Humana e Genética, Maringá.

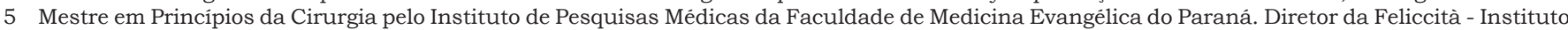
de Fertilidade, Curitiba.

6 Doutor em Patologia pela Universidade de Mie, U MIE, Japão. Professor Adjunto de Anatomia Patológica da PUCPR e UFPR.

Correspondência: Beatriz Angélica Charlotte Thomaz

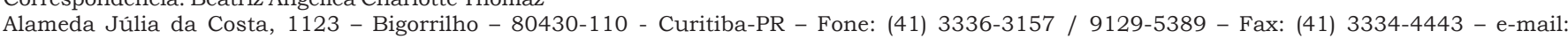
biaact@hotmail.com ou feliccita@feliccita.com.br

Recebido em: 5/8/2005 Aceito com modificações em: 30/11/2005

Rev Bras Ginecol Obstet. 2005;27(11): 642-9 
levels ( $\mathrm{p}=0.210$ ). The immunohistochemical analysis showed PCNA staining of follicles at different stages of development in the fresh tissue and primordial follicles in the cryopreserved tissue, indicating the presence of active DNA in both tissues. Conclusion: in the cryopreserved ovarian tissue the following were observed: survival of only primordial follicles; significant reversible histologic alterations (cytoplasmic vacuolation, stromal lysis and oocytes with irregular contours); irreversible alterations (hyalin degeneration and pyknosis), and PCNA staining of all follicles.

KEYWORDS: Cryopreservation; Ovary/anatomy \& histology; Ploriferating cell nuclear antigem; Rabbits

\section{Introdução}

O ovário contém reserva de células germinativas que excede o número de folículos suficiente para todos os ciclos menstruais. Esse estoque é definido antes do nascimento e não pode ser reposto. Atualmente não há metodologia comprovada para impedir o declínio da reserva folicular, embora o processo de criopreservação permita opção para a manutenção, a longo prazo, dos oócitos. A tecnologia de criopreservação pode potencialmente ser utilizada para preservar a fertilidade em pacientes a serem submetidos a tratamentos que levem à esterilização ou que tenham risco de menopausa precoce.

A criopreservação do esperma permite aos homens jovens, submetidos a tratamentos de câncer, preservar sua fertilidade ${ }^{1}$. O congelamento de tecido ovariano apresenta o mesmo objetivo para mulheres e poderia ser, também, opção para pacientes pediátricos. Entretanto, somente os folículos primordiais sobrevivem após o congelamento e a maturação folicular é necessária após o descongelamento. Este processo de maturação não foi realizado ainda em seres humanos; casos de gravidez foram obtidos somente em modelos animais.

Os fragmentos de tecido ovariano podem ser obtidos por biópsia coletada por laparoscopia ou pela dissecção total do córtex do ovário ${ }^{2}$. O congelamento tem sido feito, recentemente, com resultados muito satisfatórios, mantendo a viabilidade do tecido germinativo ${ }^{2-4}$.

A restauração da fertilidade, com o uso do tecido criopreservado, é ainda hipotética e não existe protocolo consensual para atingir esse objetivo ${ }^{5}$. Três alternativas foram descritas como possiveis: autotransplante ovariano ${ }^{6,7}$, transplante heterólogo ovariano ${ }^{8}$ e maturação de folículos ovarianos primordiais in vitro ${ }^{9,10}$. Nos casos em que se pretende utilizar o tecido ovariano para criopreservação ou para bancos de gametas, é importante a manutenção de sua integridade e da viabilidade. Para a avaliação da morfologia e funcionalidade folicular, os pesquisadores têm utilizado técnicas diversas como a análise histológica após coloração com hematoxilina-eosina ${ }^{3,8,11}$, técnica de fluorescência por microscopia eletrônica ${ }^{12}$, análise citológica de esfregaço vaginal ${ }^{13}$, análise histológica e dosagens séricas de FSH e $\mathrm{LH}^{14,15}$ e análises imuno-histoquímicas com marcadores, como o antígeno nuclear de proliferação celular - PCNA

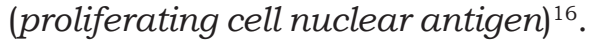

$\mathrm{O}$ atual conhecimento dos mecanismos reguladores do ciclo celular tem levado à descoberta de alguns antígenos celulares expressos em células em proliferação (marcadores de proteínas), que podem ser identificados por métodos imunohistoquímicos, por meio da utilização de anticorpos específicos para esses antígenos ${ }^{17}$. O PCNA é um desses marcadores e tem sido utilizado em estudos mostrando resultados promissores, principalmente como marcador diferencial entre lesões benignas e malignas. Uma grande vantagem desse marcador é a possibilidade de utilização em tecidos fixados pelo formol e incluídos em parafina, o método mais utilizado no preparo dos tecidos para exames histopatológicos.

A criopreservação de tecido ovariano poderá vir a ser de grande valia, quando realizada em procedimentos de ooforectomia profilática, quando houver necessidade de quimioterapia com agentes alquilantes em grandes doses ou quando a radiação pélvica é necessária, ou ainda nas situações que exijam radio e quimioterapia associadas, podendo ser alternativa para a conservação da fertilidade.

O presente estudo analisa os aspectos histológicos do ovário de coelhas após criopreservação, bem como avalia a preservação folicular desse tecido, comparada ao tecido não congelado.

\section{Métodos}

Após a aprovação do projeto, que constitui estudo retrospectivo de histologia experimental, pelo Comitê de Ética de Pesquisa com Animais da Universidade Estadual de Maringá e da Pontificia Universidade Católica do Paraná, dez coelhas brancas, da linhagem Nova Zelândia, multiparas, foram anestesiadas com aceprazina $0,2 \%-0,2 \mathrm{~mL} /$ 
$\mathrm{kg}$, acedopina $0,1 \mathrm{~mL} / \mathrm{kg}$ e cloridrato de 2-2,6xilidina diidrotiazina $3 \mathrm{mg} / \mathrm{kg}$ e receberam analgesia com cloridrato de quetamina 10\% - 35 $\mathrm{mg} / \mathrm{kg}$, intramuscular.

Efetuou-se laparotomia mediana de cinco centímetros, inventariou-se a cavidade abdominal, pois animais com doenças seriam desprezados, e identificaram-se os ovários. Realizou-se a ooforectomia direita e fez-se a revisão da hemostasia. Seguiu-se a laparorrafia. O ovário direito, depois de removido, foi dissecado, mantendo-se o córtex com a espessura de aproximadamente 1,5 milimetros, e lavado diversas vezes em solução salina tamponada fosfatada (PBS) à temperatura ambiente, a fim de se remover o excesso de sangue. O tecido foi fragmentado em pequenas secções. Alguns segmentos de cada ovário foram reservados para estudo histológico e outros foram congelados de acordo com o protocolo de congelamento lento/rápido descongelamento. As secções foram colocadas em PBS com glicose e piruvato contendo dimetilsulfóxido (DMSO) a $1,5 \mathrm{M}$ e soro bovino fetal a $10 \%$. Fez-se a homogeneização por 30 minutos a $4^{\circ} \mathrm{C}$ e introduziram-se as secções em payettes. Iniciou-se o congelamento a $4^{\circ} \mathrm{C}$ e atingiu-se a temperatura de $-9^{\circ} \mathrm{C}$ em freezer programável (Biocool $\left.{ }^{\circledR}\right)$, com diminuição da temperatura de $2^{\circ} \mathrm{C}$ por minuto. Seguiu-se a indução da cristalização com o toque de um dos lados do payette com fórcipe previamente refrigerado em nitrogênio líquido e, após 5 minutos, continuou-se o processo com diminuição da temperatura até $-40^{\circ} \mathrm{C}$, a $0,3^{\circ} \mathrm{C}$ por minuto. $\mathrm{O}$ tecido foi então transferido para nitrogênio líquido a $-196^{\circ} \mathrm{C}$.

Seis semanas após esse procedimento, colocaram-se os payettes, com tecido ovariano congelado, à temperatura ambiente por dois minutos e então se imergiu em água a $37^{\circ} \mathrm{C}$ até a fusão do gelo (dois a três minutos). Retiraram-se as secções de tecido dos payettes e removeu-se a solução crioprotetora com repetidos banhos de meio PBS com glicose e piruvato. Fixaram-se as amostras do tecido criopreservado por dois dias em formalina tamponada a 10\%. Seguiu-se a preparação dos blocos de parafina das peças não congeladas e das criopreservadas e descongeladas, dos quais se obtiveram cortes com três micrômetros de espessura e montaram-se estes cortes histológicos em lâminas. Procedeu-se à coloração pela hematoxilina-eosina para estudo histológico geral e ao método imuno-histoquímico para avaliação da preservação e desenvolvimento folicular pela técnica de PCNA. Utilizou-se o método da estreptavidina-biotina, usando-se o anticorpo antiPCNA (PC-10 - Dako ${ }^{\circledR}$ A/S. Denmark - diluição: $1: 100)$.
Nos cortes corados com hematoxilina-eosina estudaram-se as características nucleares e citoplasmáticas dos folículos e das células da camada lútea e do estroma e analisaram-se as condições histológicas do tecido conjuntivo do ovário e a vascularização.

Os folículos foram classificados de acordo com o critério modificado de Oktay et al. ${ }^{16}$. De acordo com esta classificação, folículos primordiais apresentam uma camada de células retangulares pré-granulosas ao redor do oócito (células esparsas); os primários têm ao menos uma das camadas de células pré-granulosas cubóide ou colunar, até que formem uma única camada de células granulosas cubóides; os secundários apresentam duas ou mais camadas de células granulosas envolvendo o oócito, sem formação de antro, e os foliculos antrais são constituídos de três ou mais camadas de células granulosas, com cavidade antral.

Nos cortes histológicos corados pela hematoxilina-eosina foram investigadas alterações celulares importantes na determinação do índice de preservação celular: lise estromal, que indica, indiretamente, a menor possibilidade de regeneração e maior de cicatrização; distribuição irregular da cromatina, alteração da permeabilidade da membrana plasmática a corantes não vitais e vitais indicando dissolução citoplasmática lenta, sem os fenômenos abruptos que caracterizam a citólise ${ }^{18}$; lise celular, que ocorre quando proteínas citolíticas criam poros na membrana da célula que, sendo incapaz de excluir íons e água, determina expansão osmótica levando à morte por arrebentamento; picnose, quando o núcleo apresenta volume reduzido e torna-se hipercorado, tendo sua cromatina condensada, característico na apoptose; cariólise ou cromatólise, em que há dissolução da cromatina e perda da coloração do núcleo, o qual desaparece completamente; degenerações hialinas, decorrentes da produção e do acúmulo de proteínas no interior de células ou em tecidos, que tomam aspecto hialino (homogêneo e eosinófilo); vacuolização citoplasmática, processo que ocorre devido à entrada de fluido extracelular e de eletrólitos na célula, secundária à deficiência na atividade das enzimas de degradação da adenosina trifosfato - ATPases (bombas de Na/K) da membrana celular, levando ao acúmulo de água no citoplasma (reversivel, desde que não muito intensa ou prolongada) e atrofia, diminuição adquirida do volume de um órgão ou tecido normalmente desenvolvido, pela redução no número ou no volume das células, ou ambos ${ }^{19}$.

Quantificou-se o índice de expressão do PCNA pela observação dos núcleos celulares marcados e 
não marcados com anticorpo monoclonal antiPCNA em cada corte histológico. Para este experimento, consideraram-se PCNA-positivos todos os núcleos com coloração nuclear acastanhada. Para a análise imuno-histoquímica contaram-se 100 células da camada de células lúteas, 100 células estromais e verificaram-se os folículos com ao menos uma célula da granulosa PCNA positiva, sendo esses considerados como apresentando desenvolvimento inicial. Conduziu-se este processo em microscópio óptico comum munido de lente ocular de 10 aumentos e objetiva de 40 aumentos, com magnificação final de 400 aumentos (Nikon-Eclipse ${ }^{\circledR}$ E 200). Calculou-se a porcentagem de células PCNA positivas e negativas para as células estromais e lúteas de cada lâmina.

Recorreu-se à análise descritiva dos dados por meio de tabela e gráfico. Para avaliar a preservação folicular e as características celulares do tecido ovariano criopreservado, e comparar com o não congelado, utilizou-se o teste não-paramétrico "comparação entre duas proporções" (por meio do software "Primer of Biostatistics") e os testes paramétricos $t$ de Student e não paramétrico de Mann-Whitney. Estabeleceu-se p $\leq 0,05$ ou $5 \%$ como nível para rejeição da hipótese de nulidade.

\section{Resultados}

Nos cortes histológicos submetidos à coloração pela hematoxilina-eosina, observou-se, no tecido não congelado, a presença de todos os tipos foliculares, ao passo que nos cortes criopreservados encontraram-se exclusivamente folículos primordiais. Entre as alterações celulares, as mais freqüentes no tecido criopreservado foram: vacuolização citoplasmática $(p=0,039)$, distribuição irregular da cromatina $(\mathrm{p}=0,022)$ e oócito com contorno irregular $(\mathrm{p}=0,007)$ (Tabela 1 e Figura 1).

Tabela 1 - Características histológicas encontradas no tecido ovariano não congelado e no criopreservado, em porcentagem.

\begin{tabular}{lrrr}
\hline Características histológicas & $\begin{array}{c}\text { Tecido não } \\
\text { congelado }\end{array}$ & $\begin{array}{c}\text { Tecido } \\
\text { congelado }\end{array}$ & $\begin{array}{c}\text { Valor } \\
\text { de } \mathbf{p}\end{array}$ \\
\hline Vacuolização citoplasmática & 50,0 & 100,0 & 0,039 \\
Picnose & 0,0 & 30,0 & 0,210 \\
Lise estromal & 30,0 & 50,0 & 0,648 \\
Distribuição irregular da cromatina & 10,0 & 70,0 & 0,022 \\
Fragmentação das células da granulosa & 30,0 & 80,0 & 0,072 \\
Oócito com contornos irregulares & 10,0 & 80,0 & 0,007 \\
Degeneração hialina & 0,0 & 30,0 & 0,210 \\
\hline
\end{tabular}

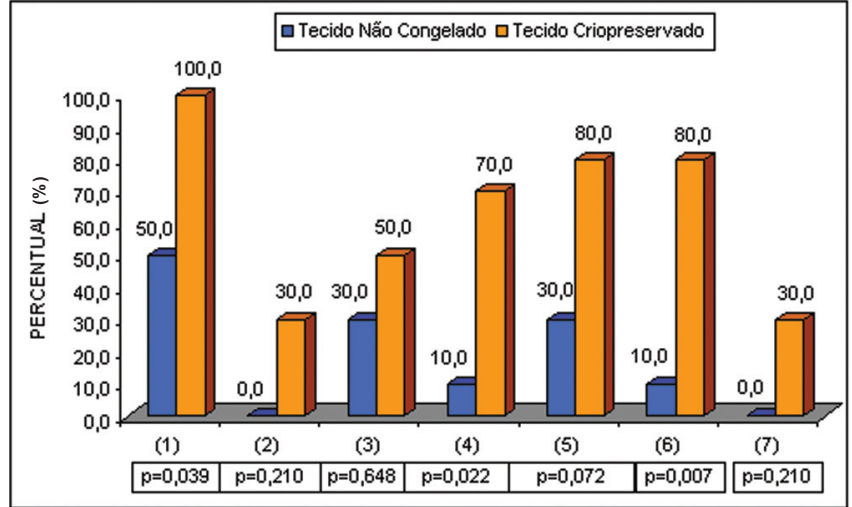

Figura 1 - Características histológicas encontradas nos dois grupos Fonte: Tabela 1

(1) Vacuolização citoplasmática

(2) Picnose

(3) Lise estromal

(4) Distribuição irregular da cromatina

(5) Fragmentação das células da granulosa

(6) Oócito com contornos irregulares

(7) Degeneração hialina

A fragmentação das células da granulosa foi mais observada nos cortes histológicos do tecido criopreservado $(p=0,072)$, no entanto, sem diferença estatisticamente significativa (probabilidade limitrofe que indica tendência). Nas Figuras 2 e 3 observam-se detalhes dos achados histológicos em tecido ovariano não congelado e criopreservado.

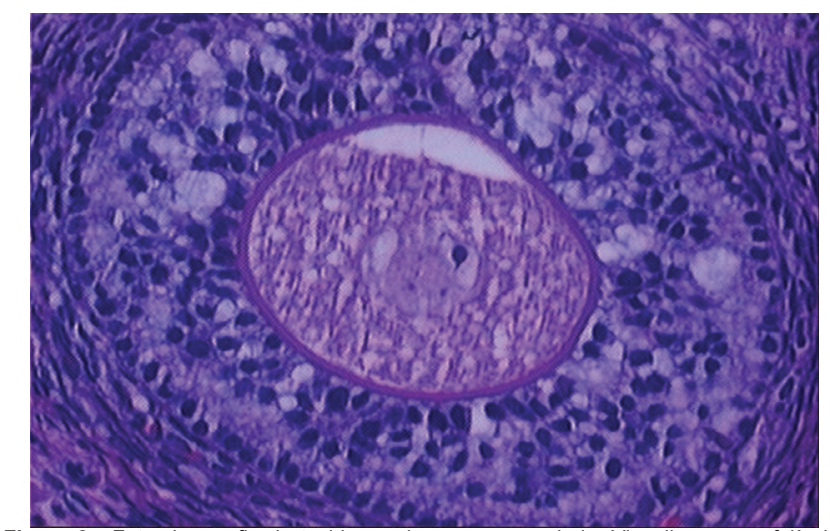

Figura 2 - Fotomicrografia de tecido ovariano não congelado. Visualiza-se um folículo secundário (HE 400X).

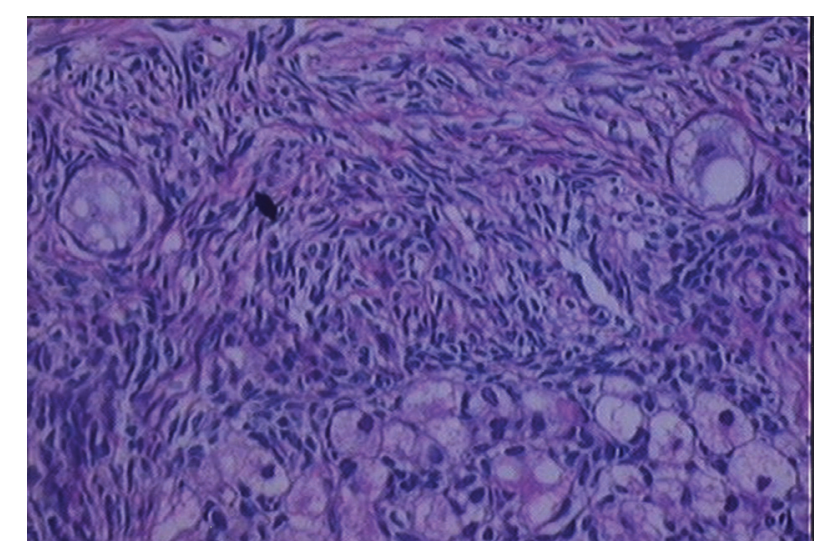

Figura 3 - Fotomicrografia de tecido ovariano criopreservado. Observam-se vários folículos primordiais (HE 400X). 
Os cortes histológicos submetidos à análise imuno-histoquímica apresentaram positividade para PCNA semelhante em tecido não congelado e tecido criopreservado. A percentagem de células lúteas positivas foi de $72,2 \pm 8,6$ no tecido não congelado e de $68,4 \pm 9,3$ no tecido criopreservado ( $p=0,355)$. Já as células estromais mostraram menor positividade; no tecido não congelado foi de $18,4 \pm 5,9$ e no criopreservado, 17,6 $\pm 9,0(p=0,543)$. Na análise comparativa em relação ao tipo de tecido pode-se afirmar que os resultados encontrados no tecido não congelado não são diferentes dos resultados encontrados no tecido criopreservado, em nenhuma das amostras analisadas (Tabela 2 e Figura 4).

Tabela 2 - Análise imuno-histoquímica pelo PCNA das células lúteas e estromais do tecido ovariano não congelado e criopreservado (\%).

\begin{tabular}{lcccccccc}
\hline Amostra & \multicolumn{3}{c}{ Tecido não congelado } & \multicolumn{4}{c}{ Tecido criopreservado } \\
& \multicolumn{2}{c}{ Células lúteas } & Células estromais & \multicolumn{2}{c}{ Células lúteas } & \multicolumn{2}{c}{ Células estromais } \\
& Positiva & Negativa & Positiva & Negativa & Positiva & Negativa & Positiva & Negativa \\
\hline 1 & 74 & 26 & 17 & 83 & 89 & 11 & 25 & 75 \\
2 & 77 & 23 & 12 & 88 & 68 & 32 & 35 & 65 \\
3 & 69 & 31 & 10 & 90 & 64 & 36 & 10 & 90 \\
4 & 74 & 26 & 16 & 84 & 62 & 38 & 12 & 88 \\
5 & 72 & 28 & 25 & 75 & 59 & 41 & 11 & 89 \\
6 & 80 & 20 & 13 & 87 & 69 & 31 & 12 & 88 \\
7 & 75 & 25 & 28 & 72 & 68 & 32 & 25 & 75 \\
8 & 63 & 37 & 18 & 82 & 80 & 20 & 10 & 90 \\
9 & 54 & 46 & 23 & 77 & 62 & 38 & 25 & 75 \\
10 & 84 & 16 & 22 & 78 & 63 & 37 & 11 & 89 \\
& & & & & & & 11 & \\
Média & 72,2 & 27,8 & 18,4 & 81,6 & 68,4 & 31,6 & 17,6 & 82,4 \\
Desvio & 8,6 & 8,6 & 5,9 & 5,9 & 9,3 & 9,3 & 9 & 9 \\
Mínimo & 54 & 16 & 10 & 72 & 59 & 11 & 10 & 65 \\
Máximo & 84 & 46 & 28 & 90 & 89 & 41 & 35 & 90 \\
Mediana & 74 & 26 & 17,5 & 82,5 & 66 & 34 & 12 & 88 \\
\%desvio & 11,9 & 30,9 & 32,3 & 7,3 & 13,6 & 29,4 & 51,3 & 10,9 \\
\hline
\end{tabular}

Células lúteas positivas - Tecido não congelado $x$ criopreservado (teste $t$ de Student, $p=0,355$ )

Células lúteas negativas - Tecido não congelado $x$ criopreservado (teste Mann-Whitney, $p=0,173$ ).

Células estromais positivas - Tecido não congelado $x$ criopreservado (teste $t$ de Student, $p=0,543$ ).

Células estromais negativas - Tecido não congelado $x$ criopreservado (teste Mann-Whitney, $p=0,817$ ).

A

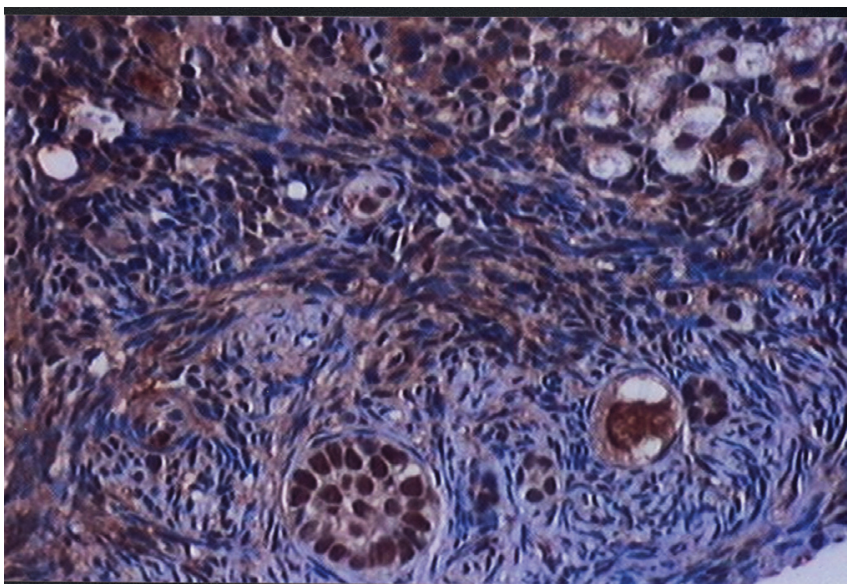

$\mathrm{B}$

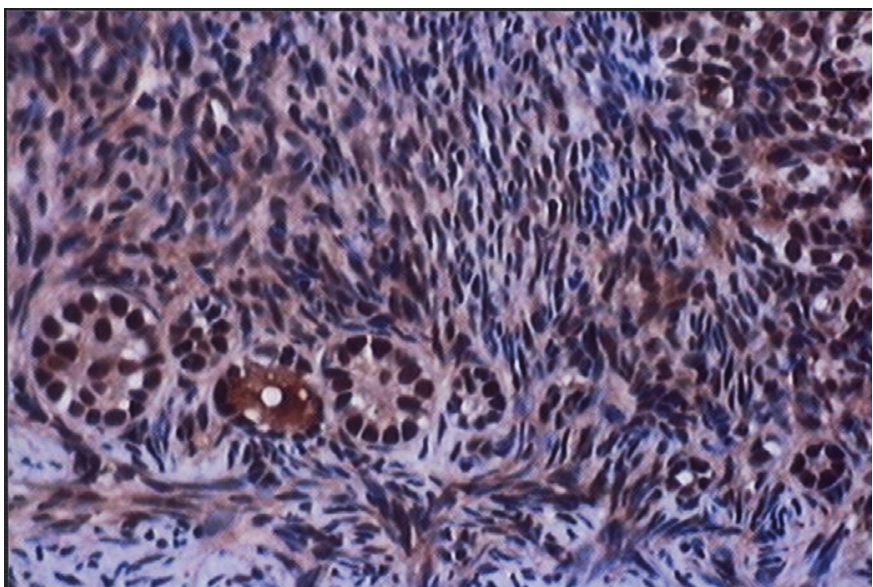

Figura 4 - Fotomicrografias demonstrando folículos primordiais e células lúteas PCNA positivas em tecido ovariano não congelado (A) e em criopreservado (B) (400X). Nota: os núcleos com positividade ao PCNA coram-se em castanho e os negativos em azul 


\section{Discussão}

A fertilidade e a sexualidade são importantes aspectos da qualidade de vida, a longo prazo, para os pacientes que se submetem a tratamento de neoplasias, especialmente crianças e adolescentes. O efeito gonadotóxico da quimioterapia é dose-dependente e relacionado com a idade do paciente. Os efeitos da radioterapia, além de estarem relacionados com a dose e com a idade, levam em conta o campo irradiado. Agentes alquilantes aumentam o risco de falência ovariana ${ }^{20,21}$.

A transposição ovariana para fora do campo da radiação, na tentativa de reduzir a esterilidade provocada pelo tratamento, nem sempre é eficaz. Estudo demonstrou que $50 \%$ das pacientes que receberam irradiação pélvica após prévia transposição ovariana apresentaram falência ovariana ${ }^{22}$.

As pacientes com câncer também podem ser submetidas à realização da fertilização in vitro (IVF) pré-quimio ou radioterapia. O problema é a falta de tempo para que a paciente se submeta à estimulação ovariana antes do início do tratamento para o câncer. Além disso, a IVF é imprópria à população pediátrica.

Outra opção é o congelamento de oócitos maduros e não fertilizados. Isto impede o dilema ético de produzir embriões "órfãos" resultantes de procedimentos de fertilização feita para paciente que não sobreviva ao câncer. Entretanto, a eficiência desta tecnologia é ainda limitada devido às baixas taxas de sucesso (aproximadamente 13\% em seres humanos). Além disso, os oócitos maduros somente podem ser coletados após o estímulo com gonadotrofinas, e em número limitado ${ }^{23}$.

A criopreservação do tecido ovariano como meio potencial de preservar a fertilidade e a função endócrina em pacientes tratados de câncer ou para mulheres em envelhecimento reprodutivo apresenta-se atualmente como grande foco de estudo. A tecnologia envolve congelar os folículos primordiais imaturos in situ no córtex ovariano.

Uma vez que o tecido ovariano é congelado, há, teoricamente, diversas opções disponiveis para sua utilização futura, incluindo autotransplante, xenoenxerto e a maturação in vitro ${ }^{24}$.

A técnica do autotransplante pode ser executada ortotopicamente ou heterotopicamente e apresenta três vantagens. Primeiramente, o tecido ovariano apresenta grande número de folículos primordiais. Uma secção de um milímetro cúbico do córtex ovariano pode conter centenas de oócitos. Em segundo lugar, o transplante autólogo de tecido ovariano preserva, teoricamente, a função endócrina das pacientes, ao contrário da IVF e da criopreservação dos oócitos, técnicas dirigidas somente à manutenção da fertilidade. Em tercei- ro lugar, a criopreservação ovariana não posterga o tratamento do câncer tanto quanto a criopreservação de embriões ou oócitos. A ooforectomia ou a biópsia ovariana podem geralmente ser feitas por laparoscopia. Os oócitos descongelados e transplantados ainda imaturos sofreriam amadurecimento in vivo, obviamente necessitando de estímulo exógeno de gonadotrofinas ${ }^{25}$.

$\mathrm{Na}$ maturação in vitro de oócitos criopreservados, considera-se que uma vez que o tecido ovariano é descongelado, teoricamente a fertilidade pode ser restaurada executando a maturação e posterior IVF. A limitação desta técnica é o escasso conhecimento sobre as circunstâncias ideais necessárias à maturação, motivo de estudo da comunidade científica mundial.

Estudos de criobiologia demonstraram que tipos diferentes de células, mesmo se congeladas na mesma solução, exibem condições de descongelamento diferentes. Este fato é especialmente relevante na criopreservação do córtex ovariano, já que os tecidos são constituídos por diversos tipos de células e cada tipo tem seu tamanho, forma e propriedades de permeabilidade característicos. Desse modo, utilizando protocolo de criopreservação que permita melhores condições de sobrevivência a um tipo de célula do córtex ovariano, pode ser que esse não seja o melhor meio de congelamento para outro tipo celular. Devido à alta complexidade da arquitetura ovariana, a sobrevivência do tecidos criopreservados depende não somente das rampas de congelamento e descongelamento, mas também dos métodos de remoção dos crioprotetores.

A criopreservação de vários tipos celulares tem sido bem descrita na literatura. De maneira geral, o bom protocolo de congelamento celular é aquele que propicia a estabilidade das reações cruzadas entre as moléculas no ambiente intracelular e também permite a sobrevivência celular após o descongelamento. O tecido deverá não somente permitir a sobrevivência celular, como também exibir a mesma arquitetura inicial, com as mesmas junções intercelulares, interações e ligações moleculares ${ }^{26}$. A dificuldade para conseguir a permeabilidade adequada dos fragmentos de tecido ao crioprotetor pode ser superada utilizando secções finas de tecido, com aproximadamente 1 a 2 milímetros de espessura, que fornecem maior área de contato para a penetração do soluto ${ }^{3}$.

Atualmente há consenso de que a recuperação após a criopreservação, usando DMSO, é de alta qualidade, com maior preservação do tecido germinativo; por este motivo utilizou-se o DMSO como crioprotetor no estudo aqui relatado.

A avaliação da viabilidade do tecido ovariano após o descongelamento pode ser feita de maneiras diversas. Vários autores utilizaram o corte 
histológico corado com hematoxilina-eosina na observação do tecido a fresco (teoricamente com histologia normal, utilizado como controle) e no tecido enxertado e recuperado. Puderam também, por meio da contagem de folículos, fazer a determinação cinética e a avaliação dos estágios de desenvolvimento folicular ${ }^{4,13,15,27}$.

Os relatos da literatura quanto à sobrevida de tecido ovariano são controversos. Recente estudo, em que os autores transplantaram para o subcutâneo de ratas tecido ovariano fresco e com duas semanas de criopreservação, demonstrou que os implantes não congelados conservaram $73 \%$ dos folículos, ao passo que os criopreservados conservaram $62 \%{ }^{28}$. Em outro estudo em que se congelaram fragmentos de ovários de ratas, foi observado que o percentual de folículos normais no tecido fresco era de $24,1 \%$ e no descongelado após duas semanas, $21,7 \%$. Os folículos com alterações eram $35,1 \%$ no tecido fresco contra $35,4 \%$ no descongelado e o percentual de morte folicular era de $40,8 \%$ no tecido fresco e de $42,8 \%$ no tecido descongela$\mathrm{do}^{29}$. Já estudo feito com ovário bovino criopreservado mostrou, após 2 semanas, que não houve dano tecidual, nem tampouco diferença entre o número de folículos primordiais e primários quando comparado ao tecido ovariano fresco ${ }^{30}$.

Nesse estudo, utilizou-se a avaliação da preservação folicular e das características celulares como critério de análise histológica do tecido ovariano criopreservado em comparação com o tecido não congelado. Observou-se que somente os folículos primordiais sobreviveram ao processo de criopreservação. Esse resultado foi semelhante ao encontrado em outras pesquisas nessa área ${ }^{24-26}$. Isso se justifica pelo fato de os folículos primordiais serem menores e metabolicamente menos ativos, portanto mais tolerantes ao processo de criopreservação. Os oócitos imaturos, presentes nos folículos primordiais, não apresentam polimerização dos microtúbulos e formação de fusos mitóticos; assim, a criopreservação de pequenos oócitos nesses folículos pode livrar as células da grande maioria dos efeitos deletérios ao $\mathrm{DNA}^{4}$.

Os cortes histológicos corados com hematoxilina-eosina permitiram a identificação das alterações histológicas presentes no tecido não congelado e no tecido criopreservado e a avaliação do potencial de viabilidade do tecido criopreservado, já que a maioria dessas alterações são reversíveis. No tecido criopreservado encontraram-se duas alterações histológicas irreversiveis, degeneração hialina e picnose, mas estas foram encontradas em apenas 30\% das amostras, justificando os resultados de recuperação da fertilidade em estudos anteriores com reimplante de tecido ovariano criopreservado.
A avaliação da viabilidade do tecido ovariano criopreservado também foi feita, nesse estudo, utilizando o PCNA, marcador sensivel dos eventos precoces de crescimento folicular. O aumento da expressão deste antígeno nos estágios iniciais de desenvolvimento das células da granulosa determina a positividade em oócitos antes de sua expansão. A imunorreação para o PCNA permanece prevalecente em folículos nas células da granulosa e da teca em estágios subseqüentes do desenvolvimento folicular e diminui progressivamente na atresia ${ }^{16}$. Verificou-se a positividade para o PCNA em todos os folículos observados, tanto em tecido não congelado como em tecido criopreservado, indicando que esses não se apresentavam atrésicos. $\mathrm{Na}$ análise comparativa em relação ao tipo de tecido, pode-se afirmar que os resultados encontrados no tecido não congelado não são estatisticamente diferentes dos resultados encontrados no tecido criopreservado.

A limitação desse estudo é o fato de que a observação da integridade morfológica não é indicação fiel de que as condições funcionais das células foram mantidas após o processo de criopreservação. Entretanto, em estudo anterior desta linha de pesquisa, obteve-se a recuperação da fertilidade em ovelhas, por meio de falência ovariana induzida por radioterapia, com implante subcortical de tecido germinativo criopreservado. Seis meses após o procedimento, as ovelhas que receberam os implantes tornaram-se espontaneamente prenhas, ao passo que as ovelhas submetidas à radioterapia, e que não receberam o implante, não apresentaram gestação até um ano e meio após o experimento, ou seja, as células do tecido criopreservado mantiveram as suas características funcionais ${ }^{31}$.

A análise comparativa dos resultados, nas condições deste experimento, permite concluir que, no tecido ovariano criopreservado, encontram-se somente folículos primordiais. A predominância de alterações histológicas reversiveis sobre as irreversíveis e a presença de reação PCNA positiva em todos os folículos, indicando a presença de DNA ativo e determinando, conseqüentemente, a viabilidade das células, permitem pensar em um futuro próximo promissor quanto às possibilidades de preservação da fertilidade feminina, diante dos tratamentos rádio e quimioterápicos.

\section{Conflito de interesse nenhum}




\section{Referências}

1. Goldberg JM, Mascha E, Falcone T, Attaran M. Comparison of intrauterine and intracervical insemination with frozen donor sperm: a metaanalysis. Fertil Steril. 1999;72(5):792-5.

2. Gosden RG. Low temperature storage and grafting of human ovarian tissue. Mol Cell Endocrinol. 2000;163(1-2):125-9.

3. Newton H, Aubard Y, Rutherford A, Sharma V, Gosden R. Low temperature storage and grafting of human ovarian tissue. Hum Reprod. 1996;11(7):1487-91.

4. Hovatta O, Silye R, Krausz T, Abir R, Margara R, Trew $\mathrm{G}$, et al. Cryopreservation of human ovarian tissue using dimethylsulphoxide and propanediol-sucrose as cryoprotectants. Hum Reprod. 1996;11(6):1268-72.

5. Salle B, Demirci B, Franck M, Rudigoz RC, Guerin $\mathrm{JF}$, Lornage J. Normal pregnancies and live births after autograft of frozen-thawed hemi-ovaries into ewes. Fertil Steril. 2002;77(2):403-8.

6. Aubard Y, Lavignac C, Grandjean MH, Piver P, Teissier MP. Autogreffes orthotopiques de fragments ovariens chez le rat avec grossesses. Contracept Fertil Sex. 1996;24(11):852-5.

7. Aubard Y, Piver P, Cogni Y, Fermeaux V, Poulin N, Driancourt MA. Orthotopic and heterotopic autografts of frozen-thawed ovarian cortex in sheep. Hum Reprod. 1999;14(8):2149-54.

8. Oktay K, Newton H, Gosden RG. Transplantation of cryopreserved human ovarian tissue results in follicle of frozen growth initiation in SCID mice. Fertil Steril. 2000;73(3):599-603.

9. Cortvrindt R, Smitz J, Van Steirteghem AC. In-vitro maturation, fertilization and embryo development of immature oocytes from early preantral follicles from prepuberal mice in a simplified culture system. Hum Reprod. 1996;11(12):2656-66.

10. Picton HM, Gosden RG. In vitro growth of human primordial follicles from frozen-banked ovarian tissue. Mol Cell Endocrinol. 2000;166(1):27-35.

11. Lundy T, Smith P, O'Connell A, Hudson NL, McNatty KP. Populations of granulosa cells in small follicles of the sheep ovary. J Reprod Fertil. 1999;115(2):251-62.

12. Baird DT, Webb R, Campbell BF, Harkness LM, Gosden RG. Long-term ovarian function in sheep after ovariectomy and transplantation autografts stored at $-196^{\circ} \mathrm{C}$. Endocrinology. 1999;140(1):462-71.

13. Candy CJ, Wood MJ, Whittingham DG. Follicular development in cryopreserved marmoset ovarian tissue after transplantation. Hum Reprod. 1995;10(9):2334-8.

14. Salle B, Lornage J, Franck M, Isoard L, Rudigoz RC, Guerin JF. Freezing, thawing, and autograft of ovarian fragments in sheep: preliminary experiments and histologic assessment. Fertil Steril. 1998;70(1):124-8.

15. Nisolle M, Casanas-Roux F, Qu J, Motta P, Donnez J. Histologic and ultrastructural evaluation of fresh and frozen-thawed human ovarian xenografts in nude mice. Fertil Steril. 2000;74(1):122-9.
16. Oktay K, Schenken RS, Nelson JF. Proliferating cell nuclear antigen marks the initiation of follicular growth in the rat. Biol Reprod. 1995;53(2):295-301.

17. Huang WY, Coltrera M, Schubert M, Morton T, Truelove E. Histophatologic evaluation of proliferating cell nuclear antigen (PC10) in oral epithelial hyperplasias and premalignant lesions. Oral Surg Oral Med Oral Pathol. 1994;78(6):748-54.

18. Santa Rosa GL. Conceito de apoptose [sitio da Internet]. 2004 [citado 2004 Maio 7]. Disponivel em: http://multipolo.com.br/histologia/apoptose.htm.

19.Vasconcelos AC. Patologia geral em hipertexto. Belo Horizonte: Universidade Federal de Minas Gerais; 2000.

20. Howell S, Shalet S. Gonadal damage from chemotherapy and radiotherapy. Endocrinol Metab Clin North Am. 1998;27(4):927-43.

21. Beerendonk CC, Braat DD. Present and future options for the preservation of fertility in female adolescents with cancer. Endocr Dev. 2005;8:166-75.

22. Feeney DD, Moore DH, Look KY, Stehman FB, Sutton GP. The fate of the ovaries after radical hysterectomy and ovarian transposition. Gynecol Oncol. 1995;56(1):3-7.

23. Blumenfeld Z, Avivi I, Linn S, Epelbaum R, BenShahar M, Haim N. Prevention of irreversible chemotherapy-induced ovarian damage in young women with lymphoma by a gonadotrophin-releasing hormone agonist in parallel to chemotherapy. Hum Reprod. 1996;11(8):1620-6.

24. Lee D, Ouhibi N, Battaglia D. Cryopreservation of ovarian tissue: banking reproductive potential for the future. Curr Womens Health Rep. 2001;1(2):152-6.

25. Meirow D, Fasouliotis SJ, Nugent D, Schenker JG, Gosden RG, Rutherford AJ. A laparoscopic technique for obtaining ovarian cortical biopsy specimens for fertility conservation in patients with cancer. Fertil Steril. 1999;71(5):948-51.

26.Pegg DE. Cryopreservation: a perspective. In: Rifle G, Vuitton D, Herve P, editors. Organ transplantation and tissue grafting. London: John Libbey; 1996. p. 375-8.

27. Sztein J, Sweet H, Farley J, Mobraaten L. Cryopreservation and orthotopic transplantation of mouse ovaries: new approach in gamete banking. Biol Reprod. 1998;58(4):1071-4.

28. Lee RK, Ho HY, Yu SL, Lu CH. Blastocyst development after cryopreservation of mouse ovarian tissue. J Assist Reprod Genet. 2005;22(2):95-101.

29. Maltaris T, Dimmler A, Müller A, Binder H, Hoffmann I, Kohl J, et al. The use of an open-freezing system with self-seeding for cryopreservation of mouse ovarian tissue. Reprod Domest Anim. 2005;40(3):250-4.

30. Lamaita RN, Bambirra EA, Camargos MG, Silva-Filho AL, Reis FM, Camargos AF. Histological evaluation of the effects of cryopreservation in bovine ovarian tissue. J Assist Reprod Genet. 2005;22(2):105-6.

31. Almodin CG, Minguetti-Camara VC, Meister H, Ceschin AP, Kriger E, Ferreira JO. Recovery of natural fertility after grafting of cryopreserved germinative tissue in ewes subjected to radiotherapy. Fertil Steril. 2004;81(1):160-4. 